\title{
Influence of Rosemary Extract on the Oxidative Stability of Tuna Orbital Oil and on the Effect in vivo of the Oxidized Oil on Rat Liver
}

\author{
Keiko YoshiokA ${ }^{* 1}$, Ai YAMAdA ${ }^{* 1}$ and Shun WADA ${ }^{* 2}$ \\ * 1 Department of Food and Nutrition, Nakamura Gakuen University \\ (5-7-1 Befu, Jonan-ku, Fukuoka 814-0198, JAPAN) \\ * 2 Department of Food Science and Technology, Tokyo University of Fisheries \\ (4-5-7 Konan, Minato-ku, Tokyo 108-8477, JAPAN)
}

Edited by K. Takahashi, Hokkaido Univ., and accepted September 19, 2001 (received for review August 20, 2001)

\begin{abstract}
Rosemary extract was added to tuna orbital oil (fish oil) to restrain oxidation, and both the peroxide value (PV) and the fatty acid composition of the fish oil were determined under autoxidation conditions. The oxidative stability of fish oil added with rosemary at levels of $0.02 \%$ or $1.0 \%$ of rosemary extract $(\mathrm{w} / \mathrm{w})$ was more effective compared to the original fish oil under autoxidation for 8 days at $20^{\circ} \mathrm{C}$, which thus demonstrated the antioxidative ability of rosemary. Further, rosemary extract was added to the diet of rats and the influence of the oxidized fish oil on the liver lipids and fatty acid was examined. The lipid content and PV of the liver lipid of rats administered oxidized fish oil and rosemary did not show much difference among experimental groups. The changes in the fatty acid composition in rat liver lipid were considered to reflect the metabolism of unsaturated fatty acids in vivo.
\end{abstract}

J. Oleo Sci., 51, 73-81 (2002).

Key words: tuna orbital oil (fish oil), oxidative stability, peroxide value, autoxidation, rosemary

\section{Introduction}

Polyunsaturated fatty acids such as icosapentaenoic acid (EPA) and docosahexaenoic acid (DHA) which are present in large quantities in the orbital oil of tuna are today added to various food products because of their beneficial physiological functions. Many researchers have shown that the intake of fish oil rich in EPA and DHA lowers the serum lipids levels of triacylglycerol (1-4). However, it is also known that these fatty acids are readily oxidized and unstable owing to their many double bonds (5). In addition, hydroperoxides, the primary product of lipid oxidation, have also been considered to be toxic $(6,7)$. Although there are reports on the oxidative stability of fish oil and on the fatty acid com-

Corresponding author: Keiko YoSHIOKA

E-mail: yoshioka@cc.nakamura-u. ac.jp position in terms of EPA and DHA $(8,9)$, there are few reports on the influence of the oxidized fish oil on the biochemistry or pathology of rats (10-12).

In order to restrain the oxidation of fats and lipids in food, antioxidants such as BHA, BHT and $\alpha$-tocopherol have been extensively used. Herbs and spices which are natural antioxidants have also been investigated. The perilla family of plants such as rosemary and sage, the family of polygonum and the family of chrysanthemum provide herbs known to be strong antioxidants (13). Nakatani et al. $(14,15)$ isolated six kinds of diterpene compounds with a phenol group and determined their structures, and also reported rosemary extracts to have high antioxidant activities, which increased proportionally as the concentration was increased.

In this study we have focused on the lipid peroxides produced in fish oil, and have determined the hydroperoxide content, which is the primary product from the 
oxidation of fish oil, and thus useful as the index of the degree of oxidation. The changes in the hydroperoxide content and fatty acid composition of tuna orbital oil (fish oil), induced by either autoxidation in air or by heating with air were examined, and the oxidative stability was investigated. Rosemary extract, which contains carnosol as one of the diterpene compounds that has a specific antioxidative effect, was added to the fish oil to examine the antioxidative effect of rosemary when the mixed lipids were oxidized. Furthermore, the oxidized fish oil was administered to rats and the antioxidative effects of rosemary in the diet on rat liver lipids were investigated.

\section{Materials and Methods}

\section{$2 \cdot 1$ Oxidative Stability of Tuna Orbital Oil (fish oil)}

$2 \cdot 1 \cdot 1 \quad$ Fish oil stored at various temperatures

Tuna orbital oil (fish oil) was prepared at Kyowa Texnos Co. (Chiba, Japan). All antioxidant in the fish oil was removed and the peroxide value (PV) of the oil was less than 1.0. The fish oil was put into screwcapped brown test tubes and each of them was stored at $-30^{\circ} \mathrm{C}$ (freezer), $4^{\circ} \mathrm{C}$ (refrigerator), $20^{\circ} \mathrm{C}$ (room), and $40^{\circ} \mathrm{C}$ (incubator) and then their degrees of oxidation were determined. Furthermore, the fatty acid composition at the maximum values of PV was also determined. To observe the changes with the passage of time at $100^{\circ} \mathrm{C}$, the fish oil was also put into screw-capped test tubes and heated for 30,60 , and $120 \mathrm{~min}$ in a block heater (Taitech, Tokyo, Japan) and the various oxidative degrees were then determined.

\section{$2 \cdot 1 \cdot 2$ Degree of oxidation of fish oil}

Measurement of lipid hydroperoxides was based on triphenylphosphine oxidation. After the reduction of hydroperoxide with triphenylphosphine (TP), fish oil and the extracted lipids were analyzed by high performance liquid chromatography (HPLC). The analysis of triphenylphosphine oxide (TPO) was performed with a Shimadzu LC-10AD HPLC system (Shimadzu Co. Ltd., Kyoto, Japan). The HPLC condition was as follows: the column was a Nova-pack Silica column (3.9 $\mathrm{mm}$ i.d. $\times 150 \mathrm{~mm}$ ), the solvent system was $\mathrm{n}$-hexane/2-propanol $(98: 2 \mathrm{v} / \mathrm{v})$ pumped at a flow rate of 1.5 $\mathrm{mL} / \mathrm{min}$ and TPO was detected by a UV detector at 220 $\mathrm{nm}$ wave length. The peroxide value (PV) was then calculated.

\section{$2 \cdot 1 \cdot 3$ Analysis of fatty acid composition}

The fish oil and the extracted lipids from rat liver were converted to their fatty acid methyl esters by heating the lipids in a mixture of solvent and 5\% $\mathrm{HCl}-$ methanol solution at $90^{\circ} \mathrm{C}$ for $120 \mathrm{~min}$. The fatty acid composition was analyzed by gas-liquid chromatography (GC) (Shimadzu GC-14A, Shimadzu Co. Ltd., Kyoto, Japan) on a glass capillary column $(30 \mathrm{~m} \times 2.5$ $\mathrm{mm}$ i.d., Ulbon HR-SS10). The gas chromatographic conditions were as follows: oven temperature $215^{\circ} \mathrm{C}$, injection port temperature $250^{\circ} \mathrm{C}$, and flame ionization detector temperature $250^{\circ} \mathrm{C}$. Each fatty acid was identified by GC-mass spectrometry (Hewlett Packard 5890, Series II). The GC-MS condition was set as follows: capillary column, DB-1 $(0.25 \mathrm{~mm}$ i.d. $\times 15 \mathrm{~m})$, oven temperature $150^{\circ} \mathrm{C}$, injection port temperature $220^{\circ} \mathrm{C}$, and flame ionization detector at temperature of $220^{\circ} \mathrm{C}$ $\left(10^{\circ} \mathrm{C} / \mathrm{min}\right)$. Helium was used as the carrier gas at $\mathrm{GC}$ and GC-MS.

\subsection{Test of Rosemary as an Antioxidant}

The food grade extract of rosemary (Molutsuka $10 \mathrm{p}$ in a paste form) which was obtained from Asama Chem. Co. (Tokyo, Japan), was added to the fish oil at levels of $0.02 \%$ and $1.0 \%$ of rosemary in fish oil. These were compared with fish oil free of antioxidants. The method of oxidation was autoxidation and they were held in the dark and oxidized at $20-22^{\circ} \mathrm{C}$ for 6 to 7 days automatically by stirring, while oxygen was provided by an air pump during the period of time. The degrees of oxidation were examined after 50-200 hours of storage and the changes in fatty acid compositions were examined.

\subsection{Administration of Oxidized Fish Oil to Rats}

$2 \cdot 3 \cdot 1$ Sample preparation of fish oils

Sample No. 1 was prepared from tuna orbital oil (fish oil) with a PV of 1.0 , while sample No. 2 of PV 460.0 was prepared from sample No. 1 through the autoxidative process, which was undertaken as follows: fish oil of PV 1.0 was shaded and oxidized automatically by stirring, inletting oxygen by an air pump at the ambient temperature.

$2 \cdot 3 \cdot 2$ Administration of oxidized fish oil to the rats

A total of 18 male rats (Wistar, 4 weeks old) were divided into 3 groups and fed an AIN-93G diet (16) 
except for the fact that the soybean oil was $5.0 \%$ of the diet instead of $7.0 \%$. Three groups were orally administrered oils as follows: I: fish oil of PV $1.0,1 \mathrm{mg} /$ day; II: oxidized fish oil of PV $460.0,1 \mathrm{mg} /$ day; III: oxidized fish oil of PV $460.0,1 \mathrm{mg} /$ day, including an AIN$93 \mathrm{G}$ diet with rosemary added ( $1 \%$ of the intake). All the rats were fed for 28 days and then anesthetized with diethyl ether and dissected. Their livers were immediately removed and the contents of the lipids, the degree of oxidation and the composition of fatty acids were examined as described below.

$2 \cdot 3 \cdot 3$ The extraction of rat liver lipids

The rat liver lipids were extracted with a mixture of chloroform and methanol followed by the method of Bligh and Dyer and the liver lipids weighed.

$2 \cdot 3 \cdot 4$ Analysis of tocopherol in the rat liver

A tocopherol analysis was conducted with a HPLC system of Shimadzu 6 A. A nucleosil column 50-5, 250 $\mathrm{mm} \times 4.6 \mathrm{~mm}$ i.d., (Gasukuro Kogyo Inc., Tokyo, Japan) was used for the separation of tocopherol. The mobile phase was n-hexane : tetrahydrofuran : methanol $(92.5: 25.0: 2.5, \mathrm{v} / \mathrm{v})$ pumped at a flow rate of 1 $\mathrm{mL} / \mathrm{min}$. Tocopherol was detected by a fluorescent detector using excitation and emission wave-lengths of $298 \mathrm{~nm}$ and $325 \mathrm{~nm}$, respectively. The rat liver lipids were extracted by the Bligh and Dyer method for this analysis.

$2 \cdot 3 \cdot 5$ Analysis of the lipid class of the rat liver

The lipid class compositions from groups I, II, and III were analyzed by thin layer chromatography (TLC). The TLC developer for neutral lipid was a mixture of petroleum ether, diethyl ether, and acetic acid ( $80: 20$ : $1, \mathrm{v} / \mathrm{v})$. The solvent system for polar lipid was chloroform, methanol, water, and acetic acid $(65: 45: 2: 1$, $\mathrm{v} / \mathrm{v}$ ). The TLC plate ( Silicagel G ) used was obtained from E. Merck, AG., with a coating thickness of $0.25 \mathrm{~mm}$. After the sample was spotted and developed, a solution of saturated potassium dichromate in $75 \%$ sulfuric acid was sprayed on the TLC plate which was then heated at $130^{\circ} \mathrm{C}$ for $5 \mathrm{~min}$. The spot sample was analyzed using a Shimadzu high speed TLC scanner CS-9200 (Shimadzu Co. and Ltd., Kyoto, Japan) to determine the lipid composition quantitatively. The components in the separated bands were identified by comparison with standard lipids.

\subsection{Statistical Analysis}

Statistical analysis of the data obtained for each test was determined by the least-significant difference method. Values are means \pm SD. Difference of $p<0.01$ and $p<0.05$ were considered to be significant.

\section{Results and Discussion}

\section{$3 \cdot 1$ Oxidative Stability of Fish Oil}

$3 \cdot 1 \cdot 1$ The changes in the degree of oxidation and fatty acid composition

The hydroperoxide content was calculated by determining the amount of both the TPO produced during the reaction and the TPO consumed by the method of Nakamura and Maeda (17). The TPO peak was observed by HPLC after a retention time of $16 \mathrm{~min}$ and the peak area became larger along with the increased oxidation. PV is calculated from the area and expressed as the degree of oxidation. Fish oil consists of almost 40 individual fatty acids. Each fatty acid was analyzed and identified by GC-MS. The main fatty acids of the fish oil were myristic acid (2.2\%), palmytic acid $(13.8 \%)$, stearic acid $(2.8 \%)$, oleic acid $(24.6 \%)$, linoleic acid (1.1\%), arachidonic acid (2.5\%), EPA (6.8\%), DPA $(2.0 \%)$ and DHA $(27.5 \%)$. The fatty acid composition was calculated by the peak area of each fatty acid detected by a chromatogram as a percentage.

\section{$3 \cdot 1 \cdot 2$ Storage temperature and storage period}

Figure 1 shows the changes in the degree of the oxidation of fish oil. No changes were observed at the degree of oxidation at $-30^{\circ} \mathrm{C}$, but it had a PV of 54.0 on the 28th day at $4^{\circ} \mathrm{C}$ and the oxidized degree was a PV of 40.2 on the 14 th day at $20^{\circ} \mathrm{C}$. At $40^{\circ} \mathrm{C}$, it showed no induction period and had a PV of 36.2 on the 5th day. The oxidative stability of fish oil depended on each temperature at $-30,4,20$, and $40^{\circ} \mathrm{C}$. The fatty acid composition at the maximum PV value of each temperature is shown in Table 1. The DHA content decreased little compared with the other fatty acids.

\section{$3 \cdot 1 \cdot 3$ Heating experiment}

The degree of oxidation increased along with time at $100^{\circ} \mathrm{C}$ (Fig. 2). Although the fatty acid composition did not change noticeably, $12 \%$ and $15 \%$ of the reduction in DHA was seen at $60 \mathrm{~min}$ and $120 \mathrm{~min}$, respectively (Table 2). As a result, the changes in the fish oil appear to accelerate depending on both the storage temperature and the heating; they are moderate when the storage temperature is low, but proceed rapidly when heated to high temperatures. 


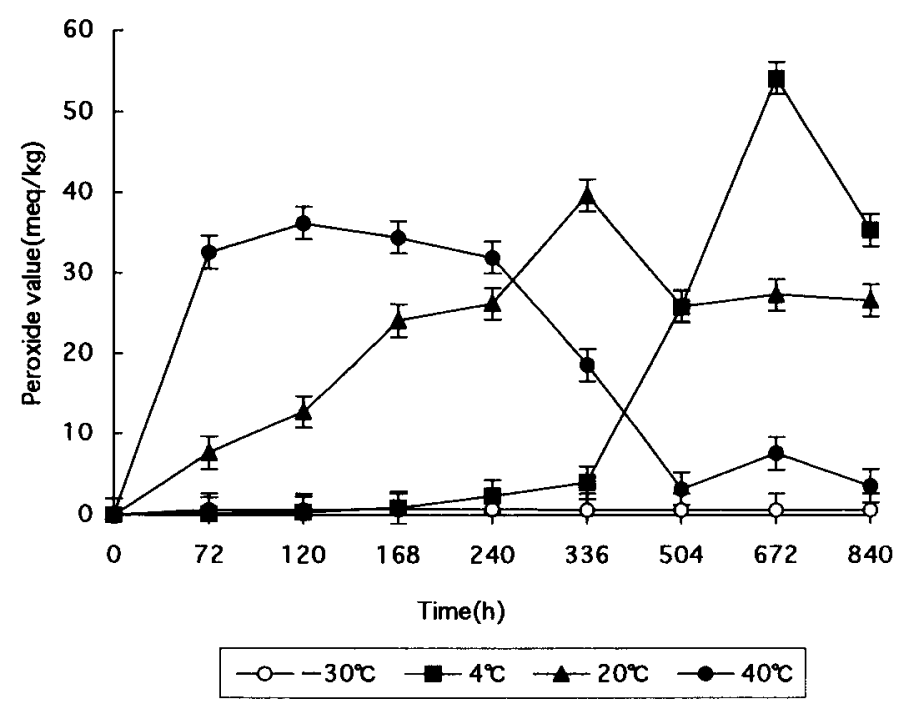

Fig. 1 Changes in the Peroxide Values of the Fish Oils with Time at Each Storage Temperature.

Values are means \pm SD of triplicate determinations.

Table 1 Changes in Peroxide Values and the Composition of Main Fatty Acids of the Fish Oil at Each Storage Temperature for the Maximum PV Observed.

\begin{tabular}{|c|c|c|c|c|c|}
\hline Temperature $\left({ }^{\circ} \mathrm{C}\right)$ & & -30 & 4 & 20 & 40 \\
\hline Storage (day) & Control & 35 & 28 & 14 & 5 \\
\hline Peroxide value (meq $/ \mathrm{kg}$ ) & $0.7 \pm 0.2$ & $0.9 \pm 0.2$ & $54.0 \pm 7.0^{* *}$ & $40.2 \pm 0.7^{* *}$ & $36.2 \pm 5.6^{* *}$ \\
\hline \multicolumn{6}{|l|}{ Fatty acid composition (\%) } \\
\hline$C_{14: 0}$ & $2.2 \pm 0.1$ & $2.1 \pm 0.1$ & $2.1 \pm 0.1$ & $2.1 \pm 0.1$ & $2.3 \pm 0.1^{*}$ \\
\hline $\mathrm{C}_{16: 0}$ & $13.8 \pm 0.6$ & $13.2 \pm 0.6$ & $13.7 \pm 0.6$ & $13.7 \pm 0.6$ & $14.5 \pm 0.6^{*}$ \\
\hline $\mathrm{C}_{18: 0}$ & $2.6 \pm 0.2$ & $2.6 \pm 0.1$ & $2.7 \pm 0.1$ & $2.7 \pm 0.1$ & $2.6 \pm 0.1$ \\
\hline$C_{18: 1(n-9)}$ & $23.9 \pm 0.7$ & $23.9 \pm 0.7$ & $23.5 \pm 1.8$ & $24.4 \pm 0.6$ & $21.2 \pm 0.8^{*}$ \\
\hline $\mathrm{C}_{18: 2(n-6)}$ & $1.1 \pm 0.0$ & $1.0 \pm 0.1$ & $1.1 \pm 0.1$ & $1.1 \pm 0.1$ & $1.0 \pm 0.0$ \\
\hline $\mathrm{C}_{20: 4(n-6)}$ & $2.6 \pm 0.1$ & $2.6 \pm 0.1$ & $2.8 \pm 0.4$ & $2.7 \pm 0.1$ & $2.8 \pm 0.2$ \\
\hline $\mathrm{C}_{20: 5(n-3)}$ & $6.8 \pm 0.1$ & $6.7 \pm 0.1$ & $7.0 \pm 0.6$ & $6.5 \pm 0.3$ & $7.3 \pm 0.4$ \\
\hline $\mathrm{C}_{22: 6(n-3)}$ & $27.5 \pm 2.0$ & $24.7 \pm 2.5$ & $23.7 \pm 2.7$ & $23.1 \pm 2.4$ & $24.1 \pm 1.9$ \\
\hline
\end{tabular}

Values are means \pm SD of triplicate determinations.

Significantly different from control fish oil; ${ }^{*}: \mathrm{P}<0.05,{ }^{* *}$ : $\mathrm{P}<0.01$.

\subsection{Effect of Addition of Rosemary on Fish Oil}

Nakatani et al. $(14,15)$ and Houlihan et al. $(18,19)$ isolated diterpene compounds (rosmaridiphenol, rosmariquinone) from a methanol extract of rosemary, and reported PV in lard added with a $0.02 \%$ concentration of rosemary extract is almost equal to the one added with the same concentration of BHT. Recently, Wada $e t$ al. (20) and Wong et al. (21) showed the antioxidant effect of rosemary in a fish oil model, the meat of fish and meat system.

In order to elucidate the antioxidative effect of rosemary in the fish oil with the addition of rosemary, 0.02 and $1.0 \%$ rosemary were added to the fish oil at $20{ }^{\circ} \mathrm{C}$. 


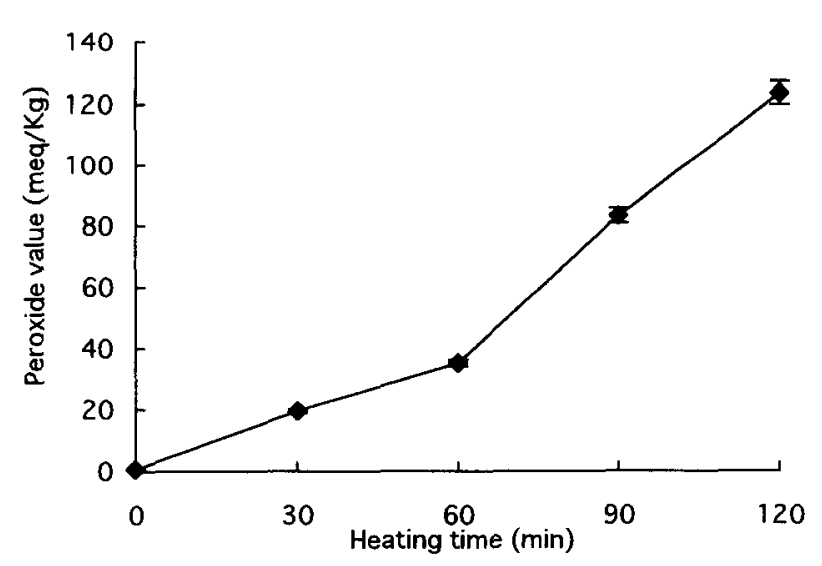

Fig. 2 Peroxide Values of Fish Oil Heated at $100^{\circ} \mathrm{C}$.

Values are means $\pm \mathrm{SD}$ of triplicate determinations.

The resulting degrees of oxidation are shown in Fig. 3 . After 150 hours (or 6 days) the PV changed to 147.0 in the fish oil with non-addition of rosemary, 52.0 in the fish oil with $0.02 \%$ added and 9.0 in the fish oil with $1.0 \%$ added. Furthermore, after 200 hours (or 8 days) the PV of the fish oil with non-addition of rosemary reached PV 1064.0, while the fish oil with $0.02 \%$ and $1.0 \%$ added changed moderately to be PV 73.0 and PV 11.0 , respectively. After being oxidized for 8 days, the $0.02 \%$ addition of rosemary controlled the oxidation of fish oil, thus showing that the PV of fish oil with nonaddition of rosemary was fifteen and one hundred times higher compared with the $0.02 \%$ and $1.0 \%$ addition of

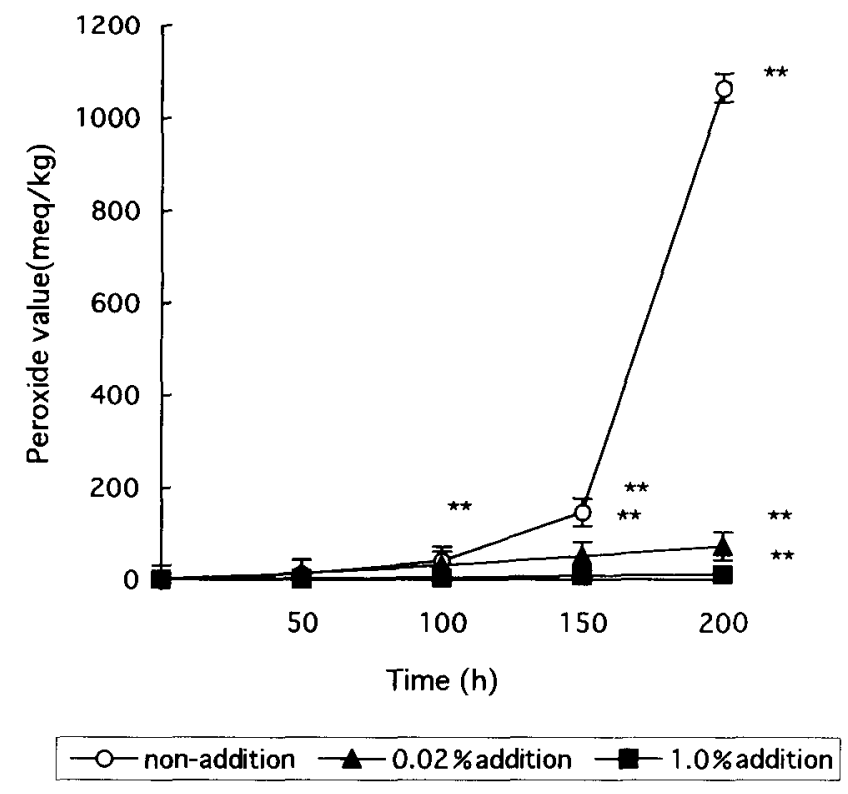

Fig. 3 Autoxidation of the Fish Oil without or with Addition of Rosemary Extract.

Values are means \pm SD of triplicate determinations. Significantly different from fish oil with nonaddtion of rosemary; ${ }^{* *}: \mathrm{p}<0.01$.

rosemary, respectively. These results obviously demonstrated an antioxidative effect of rosemary.

The compositions of the fatty acids of fish oil added and non-added with rosemary extract are shown in Table 3. EPA was $7.4 \%$ in the $0.02 \%$ addition of rose-

Table 2 Changes in Peroxide Values and the Composition of Main Fatty Acids of the Fish Oil Heated at $100^{\circ} \mathrm{C}$.

\begin{tabular}{|c|c|c|c|c|}
\hline \multicolumn{5}{|c|}{$100^{\circ} \mathrm{C}$} \\
\hline Storage (min) & 0 & 30 & 60 & 120 \\
\hline Peroxide value $(\mathrm{meq} / \mathrm{kg}$ ) & $0.7 \pm 0.2$ & $19.0 \pm 4.8$ & $35.0 \pm 5.9^{* *}$ & $124.0 \pm 21.5^{* *}$ \\
\hline \multicolumn{5}{|l|}{ Fatty acid composition (\%) } \\
\hline $\mathrm{C}_{14: 0}$ & $2.2 \pm 0.1$ & $2.3 \pm 0.1$ & $2.3 \pm 0.1^{*}$ & $2.3 \pm 0.0^{*}$ \\
\hline $\mathrm{C}_{16: 0}$ & $13.8 \pm 0.6$ & $14.4 \pm 0.4$ & $14.5 \pm 0.6$ & $14.8 \pm 0.4^{*}$ \\
\hline $\mathrm{C}_{18: 0}$ & $2.6 \pm 0.2$ & $2.5 \pm 0.1$ & $2.6 \pm 0.1$ & $2.6 \pm 0.1$ \\
\hline$C_{18: 1(n-9)}$ & $23.9 \pm 0.7$ & $21.0 \pm 0.8$ & $20.2 \pm 1.7$ & $21.3 \pm 1.0$ \\
\hline$C_{18: 2(n-6)}$ & $1.1 \pm 0.0$ & $1.0 \pm 0.1$ & $1.0 \pm 0.0$ & $1.0 \pm 0.0$ \\
\hline $\mathrm{C}_{20: 4(\mathrm{n}-6)}$ & $2.6 \pm 0.1$ & $2.8 \pm 0.2$ & $2.7 \pm 0.3$ & $2.8 \pm 0.2$ \\
\hline $\mathrm{C}_{20: 5(\mathrm{n}-3)}$ & $6.8 \pm 0.1$ & $7.3 \pm 0.2$ & $7.2 \pm 0.3$ & $7.1 \pm 0.2$ \\
\hline $\mathrm{C}_{22: 6(\mathrm{n}-3)}$ & $27.5 \pm 2.0$ & $23.5 \pm 3.0$ & $24.7 \pm 2.3$ & $24.9 \pm 0.8$ \\
\hline
\end{tabular}

Values are means \pm SD of triplicate determinations.

Significantly different from non-heated fish oil at $\mathrm{O}$ storage; ${ }^{*}: \mathrm{P}<0.05,{ }^{*}: \mathrm{P}<0.01$. 
Table 3 Changes in Fatty Acid Composition of the Fish Oil after Autoxidation without and with Rosemary Extract at 20 to $22{ }^{\circ} \mathrm{C}$.

\begin{tabular}{crcc}
\hline Rosemary extract added & \multicolumn{1}{c}{$0 \%$} & \multicolumn{1}{c}{$0.02 \%$} & \multicolumn{1}{c}{$1.00 \%$} \\
\hline Peroxide value (meq/kg) & $1064.0 \pm 2.9$ & $73.0 \pm 4.8^{* *}$ & $11.0 \pm 0.6^{* *}$ \\
\hline Fatty acid composition (\%) & & & \\
$\mathrm{C}_{14: 0}$ & $4.8 \pm 0.2$ & $3.6 \pm 0.4^{* *}$ & $3.5 \pm 0.1^{* *}$ \\
$\mathrm{C}_{16: 0}$ & $30.1 \pm 0.1$ & $22.9 \pm 2.9^{* *}$ & $22.6 \pm 0.6^{* *}$ \\
$\mathrm{C}_{18: 0}$ & $7.3 \pm 2.0$ & $5.7 \pm 0.7^{* *}$ & $5.5 \pm 0.5^{* *}$ \\
$\mathrm{C}_{18: 1(\mathrm{n}-9)}$ & $26.2 \pm 3.9$ & $20.5 \pm 5.8$ & $21.0 \pm 0.5$ \\
$\mathrm{C}_{18: 2(\mathrm{n}-6)}$ & $1.7 \pm 0.1$ & $1.8 \pm 0.2$ & $2.1 \pm 0.5$ \\
$\mathrm{C}_{20: 5(\mathrm{n}-3)}$ & $3.7 \pm 0.7$ & $7.4 \pm 2.1^{*}$ & $8.1 \pm 1.5^{*}$ \\
$\mathrm{C}_{22: 6(\mathrm{n}-3)}$ & $7.3 \pm 1.2$ & $24.1 \pm 3.4^{* *}$ & $25.4 \pm 2.0^{* *}$ \\
\hline
\end{tabular}

Values are means $\pm \mathrm{SD}$ of triplicate determinations.

Significantly different from fish oil with non-addtion of rosemary; ${ }^{*}: \mathrm{P}<0.05,{ }^{* *}: \mathrm{P}<0.01$.

Table 4 Fatty Acid Composition of Oxidized Fish Oils Administered to Rats.

\begin{tabular}{ccc}
\hline & Sample No.1 & Sample No.2 \\
\hline Peroxide value (meq/kg) & $1.0 \pm 0.3$ & $460.4 \pm 24.5^{* *}$ \\
\hline Fatty acid composition (\%) & & \\
$\mathrm{C}_{14: 0}$ & $3.1 \pm 0.0$ & $3.4 \pm 0.2$ \\
$\mathrm{C}_{16: 0}$ & $18.8 \pm 0.0$ & $20.7 \pm 0.3^{* *}$ \\
$\mathrm{C}_{18: 0}$ & $5.1 \pm 0.1$ & $5.4 \pm 0.1^{*}$ \\
$\mathrm{C}_{18: 1(\mathrm{n}-9)}$ & $18.6 \pm 1.3$ & $21.3 \pm 1.7$ \\
$\mathrm{C}_{18: 2(\mathrm{n}-6)}$ & $1.5 \pm 0.1$ & $1.4 \pm 0.1$ \\
$\mathrm{C}_{20: 5(\mathrm{n}-3)}$ & $8.3 \pm 0.1$ & $7.2 \pm 0.1^{* *}$ \\
$\mathrm{C}_{22: 6(\mathrm{n}-3)}$ & $25.0 \pm 0.2$ & $21.1 \pm 0.1^{* *}$ \\
\hline
\end{tabular}

Values are means \pm SD of triplicate determinations.

Significantly different in comparison with sample No.1 ${ }^{*}: \mathrm{P}<0.05,{ }^{*} * \mathrm{P}<0.01$.

mary, $8.1 \%$ in the $1.0 \%$ addition of rosemary and 3.7 $\%$ in fish oil with non-addition of rosemary, while little decrease in EPA between the samples of $0.02 \%$ and $1.0 \%$ addition. DHA was $24.1 \%$ in the oil with $0.02 \%$ addition of rosemary, $25.4 \%$ with in $1.0 \%$ addition of rosemary and $7.3 \%$ in the fish oil with non-addition of rosemary, which indicated a remarkable decrease in DHA.

As a result, this experiment suggested that the addition of rosemary restrained not only the degree of oxidation but also the changes in the unsaturated fatty acids, especially DHA.

\subsection{Influence of the Administration of Fish Oil on the Rat Liver}

$3 \cdot 3 \cdot 1$ Fish oil and oxidized fish oil administered to rats

Table 4 shows the fatty acid compositions of sample No. 1 fish oil of PV 1.0 and the oxidized sample No. 2 fish oil of PV 460.0. EPA was $8.3 \%$ for PV 1.0 but it was $7.2 \%$ for PV 460.0 , which was a $13 \%$ decrease compared with the sample of PV 1.0. In sample No. 1 the DHA was 25.0, while for sample No. 2 it was 21.1, which showed a $15 \%$ decrease from sample No. 1 . Though the contents of EPA and DHA changed due to autoxidation, no remarkable changes were observed in the other fatty acids. 


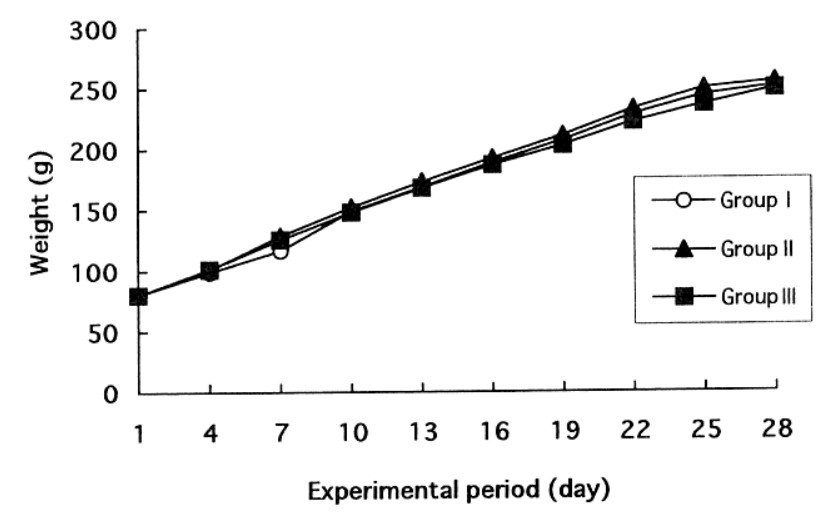

Fig. 4 The Changes in the Body Weight of Rats in Each Group.

The body weight in each group is the mean value of six rats. Six rats in each group I, II, and III were fed with the AIN-93G diet and also were orally administered; I: fish oil of PV 1.0, $1 \mathrm{mg} / \mathrm{day}$; II: oxidized fish oil of PV 460.0, $1 \mathrm{mg} /$ day; III: oxidized fish oil of PV 460.0, $1 \mathrm{mg}$ /day. Group III was fed on the AIN-93G diet with extracted rosemary $(1 \%$ of the intake).

$3 \cdot 3 \cdot 2$ The changes in the rat body weight

As shown in Fig. 4, no weight changes were noticeable among the groups I, II and III, and all rats grew normally.

$3 \cdot 3 \cdot 3$ The degree of oxidation of the rat liver lipid and the changes in fatty acid composition

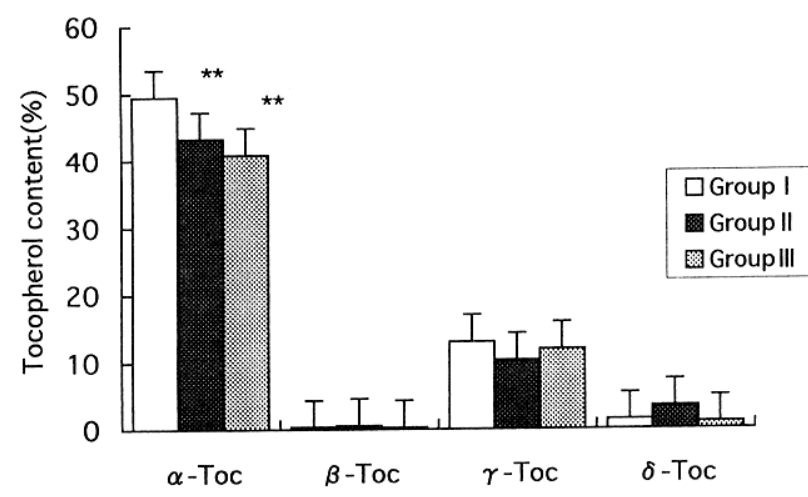

Fig. 5 The Tocopherol Content of Rat Livers after Administration of Fish Oils.

Details of Groups I, II and III are described in the footnote of Fig. 4. Values are means $\pm \mathrm{SD}$ of six rats in each group. Significantly different in comparison with Group I; $* *$ : $<0.01$.

Table 5 The Degree of Oxidation and Fatty Acid Composition of Rat Liver Lipids after Administration of the Fish Oil.

\begin{tabular}{cccc}
\hline PV of administered oil & Group I & Group II & $\begin{array}{c}\text { Group III } \\
\text { PV 460 } \\
\text { +Rosemary }\end{array}$ \\
\hline Lipids content in liver (\%/g) & PV 1.0 & PV 460 & 3.65 \\
\hline PV of liver lipid peroxide value (meq/kg) & 3.54 & 3.86 & $8.3 \pm 0.1^{* *}$ \\
\hline Lipid fatty acid compoition (\%) & $6.9 \pm 0.0$ & $10.1 \pm 0.2^{* *}$ & \\
$\mathrm{C}_{16: 0}$ & $23.3 \pm 1.1$ & $22.8 \pm 1.3$ & $23.8 \pm 0.1$ \\
$\mathrm{C}_{18: 0}$ & $19.9 \pm 0.4$ & $19.3 \pm 2.0$ & $18.9 \pm 0.1$ \\
$\mathrm{C}_{18: 1(\mathrm{n}-9)}$ & $8.9 \pm 0.1$ & $8.5 \pm 2.1$ & $6.0 \pm 0.5^{*}$ \\
$\mathrm{C}_{18: 2(\mathrm{n}-6)}$ & $13.6 \pm 0.1$ & $16.3 \pm 2.2$ & $15.2 \pm 1.1$ \\
$\mathrm{C}_{20: 4(\mathrm{n}-6)}$ & $18.2 \pm 0.2$ & $13.9 \pm 0.1 * *$ & $19.0 \pm 0.5^{*}$ \\
$\mathrm{C}_{20: 5(\mathrm{n}-3)}$ & $3.2 \pm 0.5$ & $2.4 \pm 0.5$ & $2.5 \pm 0.7^{*}$ \\
$\mathrm{C}_{22: 6(\mathrm{n}-3)}$ & $11.4 \pm 0.4$ & $10.1 \pm 1.6$ & $13.5 \pm 0.5^{*}$ \\
\hline
\end{tabular}

Details of Groups I, II, and III are described in the footnote of Fig. 4.

Values are means \pm SD of six rats in each group.

Significantly different in comparison with Group $\mathbf{I} ;{ }^{*}: \mathrm{P}<0.05,{ }^{* *}: \mathrm{P}<0.01$. 


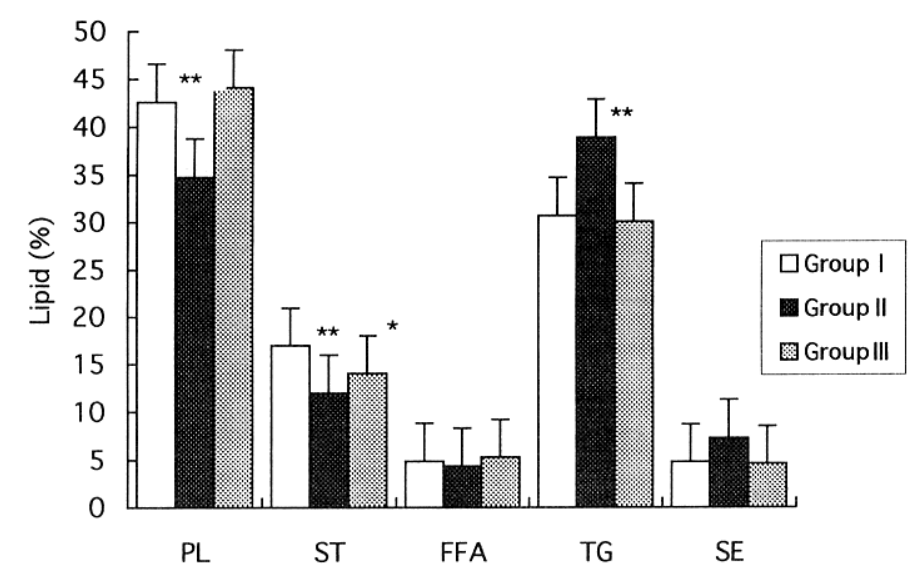

Fig. 6 The Lipid Class of Rat Liver Lipid after Administration of Fish Oil.

Details of Groups I, II and III are described in the footnote of Fig. 4. PL: phospholipid; ST: sterol; FFA: free fatty acid; TG: triacylglycerol; SE: sterol ester. Values are means $\pm \mathrm{SD}$ of six rats in each group.

Significantly different from in comparison with Group I; $*$ p $<0.05, * *: \mathrm{p}<0.01$.

1.0, while it was $10.1 \%$ in group II administered with the fish oil of PV 460.0, which was a lower level than group I. Similarly, the arachidonic acid level was $13.9 \%$ in group II, which was lower than that $(18.2 \%)$ in group. The arachidonic acid level was higher in group III at $19.0 \%$ than in group II. It is reported that the fatty acid composition of rat liver lipids depends on the resources from marine oil or plant oil in the diet $(22,23)$. These results are thought to be due to the administration of oxidized fish oil. We then further compared group III with group II, and DHA showed a high level of $13.5 \%$ in group III fed with the addition of rosemary. It is considered that this is an in vivo antioxidative effect of rosemary.

$3 \cdot 3 \cdot 4$ Tocopherol content of rat liver lipid

The content of tocopherol in the rat liver lipid is shown in Fig. 5. The total contents of $\alpha$-tocopherol and $\gamma$-tocopherol per $100 \mathrm{~g}$ of rat liver was $62.0 \mathrm{mg}$ in group I, 54.0mg in group II and 53.0mg in group III, respectively. A difference was thus noticeable between group I and groups II and III which were administered with the oxidized fish oil. It is considered that tocopherol affected the oxidized fish oil to be antioxidized in groups II and III.

$3 \cdot 3 \cdot 5$ Rat liver lipid class

Figure 6 shows the rat liver lipid class. Rat liver lipid consists mainly of PL (phospholipid) and TG (triglycerol). In groups I and III, no difference in these lipids was observed, while a large difference was seen in the contents of PL and TG in comparison with those of group II. The content of TG in group II was thus considered to increase due to the administration of the oxidized fish oil. On the other hand, the low levels of TG were thought to be caused by the good quality of fish oil of PV 1.0 in group $\mathbf{I}$ and the effect of rosemary in the diet on oxidation in group III. From these results, it is thus considered that both the administered diets and fish oil influenced the accumulation of TG in the rat liver.

The rosemary extract is utilized as an antioxidant for meat products and frying oil in food processing. If rosemary extract is added to fish oil, it works effectively in the prevention of oxidation. Since rosemary in small quantities helps remove unpleasant food smell while also enriching the taste and flavor when added to foodstuffs and also helps prevent lipid oxidation, the use of rosemary in daily cooking is thus considered to be of good advantage.

The degree of oxidation and the fatty acid composition in rat liver was not greatly affected by the fish oil of PV 460.0 administered in this experiment. It is thought that the method of oxidation for the fish oil 
administered to rats was autoxidation and the detoxication function of the livers might also simultaneously play a role. The absorption and the mechanism of detoxication of the primary products such as hydroperoxide in living bodies with the antioxidative mechanism of rosemary should be clarified in the future.

Based on the above findings, the degree of oxidation of the fish oil progressed moderately at low temperatures in storage and rapidly at high temperatures in storage and is also accelerated by heating. In the additive test of rosemary to the oxidized fish oil, a $0.02 \%$ addition of rosemary greatly restrained the oxidation of fish oil, and furthermore, a $1.0 \%$ addition of rosemary reduced it even more remarkably, and thus the antioxidative effect of rosemary was established. Though the degree of oxidation and the fatty acid composition of liver lipids of rats administered with oxidized fish oil were not greatly affected by the addition of rosemary, the group administered rosemary addition showed slightly preferable results, which thus suggested that the metabolism of the unsaturated fatty acids was accelerated.

\section{References}

1. Kobatake, Y., Kuroda, K., Junnouchi, H., Nishide, E. \& Innami, S. (1984) J. Nutr. Sci. Vitaminol., 30, 357-372.

2. Balasubramaniam, S., Simons, L. A., Chang, S. \& Hickie, J.B. (1985) J. Lipid Res., 26, 684-689.

3. Nakajima, S., Suetuna, K. \& Tsuchiya, T. (1994) Nippon Suisan Gakk., 60, 635-369.

4. Suzuki, H., Tamura, M., Wada, S. \& Crawford, M. A. (1995) Fisheries Sci, 61, 525-526.

5. Hayashi, K. \& Kishimura, H. (1996) Fisheries Sci., 62, 842-844.
6. Saito, M., Fukui, Y., Hoshino T. \& Kaneda, T. (1978) J. Jpn. Soi. Nutr. Food Sci., 31, 135-141.

7. Oarada, M. \& Miyazawa, A. (1990) The effect of rancid oils on lymphoid tissues. J. Jpn Oil Chem. Soc. (J. Oleo Sci.), 39, 373-376.

8. Miyashita, K., Takeda, N. \& Ota, T. (1994) Fisheries Sci., 60, 315-318.

9. Miyashita, K., Hirao, M., Nara, E. \& Ota, T. (1995) Fisheries Sci., 61, 273-276.

10. Paik, T. H., Hoshino, T. \& Kaneda, T. (1976) J. Jpn Oil Chem. Soc. (J. Oleo Sci.), 29, 85-94.

11. Paik, T. H. \& Kaneda, T. (1978a) J. Jpn Oil Chem. Soc. ( $J$, Oleo Sci.), 27, 851-855.

12. Paik, T. H. \& Kaneda, T. (1978b) J. Jpn Oil Chem. Soc. (J. Oleo Sci.), 27, 856-862.

13. Chang, S.S., Ostric-Matijasevic, B., Hsieh, O.A.-L. \& Huang, C.-L. (1977) J. Food Sci., 42, 1102-1106.

14. Nakatani, N. \& Inatani, R. (1983) J. Agr. Biol. Chem., 47, 353-358.

15. Nakatani, N. \& Inatani, R . (1984) J. Agr. Biol. Chem., 48, 2081-2085.

16. Philip G. Reeves, Forrest H. Nielsen \& George C. Fahey, (1993) J. Nutr., 123, 1939-1951.

17. Nakamura, T. \& Maeda, H. (1991) Lipids, 26, 765-767.

18. Houlihan, C. M., HO, C-T \& Chang, S.S. (1984) J. Am. Oil Chem. Soc., 61, 1036-1039.

19. Houlihan, C. M., HO, C-T \& Chang, S.S . (1985) J. Am. Oil Chem. Soc., 62, 96-98.

20. Wada, S. \& Fang, X. (1992) J. Food Process. Pres., 16, 263-274.

21. Wong, J.W., Hashimoto, K. \& Shibamoto, T. (1995) J. Agr. Food Chem., 43, 2707-2712.

22. Mouri, K., Ikesu, H., Esaki, T. \& Igarashi, O. (1984) J. Nutr. Sci. Vitaminol., 30, 307-318.

23. Deguchi, M., Yoshioka, K. \& Yamamoto, T. (1997) 49th Annual Meeting of Japanese Society of Nutrition and Food, Gifu, Abstract, p.98. 